\title{
REESTRUTURAÇÃO DA PRODUÇÃO AGRÍCOLA E ORGANIZAÇÃO DO ESPAÇO AGRÁRIO PIAUIENSE: O AGRONEGÓCIO DA COMMODITY SOJA
}

\author{
RESTRUCTURING OF AGRICULTURAL PRODUCTION AND ORGANIZING OF \\ PIAUIENSE AGRARIAN ESPACE: THE AGRIBUSINESS OF SOY COMMODITY \\ REESTRUCTURACIÓN DE LA PRODUCCIÓN AGRÍCOLA Y ORGANIZACIÓN \\ DEL ESPACIO AGRÁRIO PIAUIENSE: EL AGRONEGOCIO \\ DE LA COMMODITY SOYA
}

\author{
Manuela Nunes Leal - Universidade Estadual de Feira de Santana - Feira de Santana - Bahia - Brasil \\ manunlgeo@hotmail.com \\ Vera Lucia Alves França - Universidade Federal de Sergipe - Aracaju - Sergipe - Brasil \\ verafranca@gmail.com
}

\section{Resumo}

0 objetivo deste artigo é analisar a reestruturação da produção agrícola na organização do espaço agrário piauiense, com base na commodity soja. 0 encaminhamento metodológico utilizado na elaboração deste artigo baseou-se em pesquisa bibliográfica, busca de informações e dados junto ao Ministério da Integração Nacional referentes à Política Nacional de Desenvolvimento Regional e o documento sobre o polo de desenvolvimento integrado Uruçuí/Gurgueia no estado do Piauí. 0 espaço agrário do estado do Piauí, mais especificamente 0 sudoeste desse estado, tem passado por constantes transformações espaciais decorrentes da territorialização do capital à luz do agronegócio da commodity soja, conformando e consolidando regiões. Tal situação é resultante de um conjunto de ações de gestores públicos, agroindústrias, produtores e empresas que prestam serviços à cadeia produtiva do agronegócio para garantir a materialidade da produção, circulação e venda da commodity soja.

Palavras-chave: reestruturação produtiva, agronegócio, espaço agrário.

\section{Abstract}

The objective of concerned article is analyzing the restructuring of agricultural production in organizing of piauiense agrarian space, from soy commodity. The used methodological guiding in elaboration of this article was bibliography researching and search of information and data closing of National Integration Department referring to Regional Development of National Politics and the document about the pole of Uruçuí/Gurgueia integrated development in Piauí state. The agrarian space of Piauí space, more specifically in a southwest of this state, has constantly passed by spatial transformation due to territorialization of capital to light agribusiness of soy commodity that is conforming and consolidating regions. Such situation is resulted of one set of public managers' actions, agroindustries, producers and company that give services to productive chain of agribusiness for guarantee the production's materiality, circulation and selling of soy commodity.

Key words: productive restructuring, agribusiness, agrarian space.

\section{Resumen}

El objetivo del referido artículo es analisar la reestructuración de la producción agrícola en la organización del espacio agrario piauiense, a partir de La Commodity Soya. El encaminamiento metodológico utilizado en la elaboración de este artículo fue la pesquisa bibliográfica y la búsqueda de informaciones y datos junto al ministerio de la Integración Nacional referentes a la política Nacional del desarrollo integrado Uruçuí/Gurgueia en el estado del Piauí. El espacio agrario del estado del Piauí, más especificamente el sudoeste de ese Estado tiene pasado por 
constantes transformaciones espaciales decurrentes de la territorialización del capital a la luz del agronegócio de la Commodity Soya conformando y consolidando regiones. Tal situación es resultante de un conjunto de acciones de gestores públicos agroindustrias, productores y empresas que prestan servicios a la cadena productiva del agronegocio para garantizar la materialidad de la producción, circulación y venta de la Commodity Soya. Palabras clave: reestructuración productiva, agronegocio, espacio agrario.

Introdução

A conformação do agronegócio da soja e seu arranjo produtivo desencadeiam transformações espaciais em suas formas e diferentes funcionalidades, modelando e reorganizando o espaço para garantir a sua efetivação e lucratividade. O entendimento dessa organização espacial é fundamental para discutir o espaço agrário brasileiro, em especial o piauiense, que nas últimas décadas tem alterado sua base produtiva. Em razão disso, é pertinente analisar a reestruturação da produção agrícola na organização do espaço agrário piauiense, que conforma ou consolida regiões da commodity soja. Existem estudos que discutem o desenvolvimento e a modernização da agricultura, a especulação fundiária, a transição da atividade pastoril e a agricultura de subsistência para o agronegócio no estado do Piauí. Porém, ainda há questões a ser analisadas para explicação do cenário da reestruturação produtiva no setor agrícola.

A compreensão da reestruturação diz respeito à mudança na base produtiva no sudoeste piauiense. Até o início da década de 1970, a atividade agrícola existente nesse espaço eram a pastoril e a agricultura de subsistência assentadas nos vales úmidos, juntamente com a prática de uso dos platôs planos - as chapadas ou gerais, como são conhecidas pela população local - para uso de áreas de reserva para pasto, caça, extração de lenha e coleta de frutos (Alves, 2005). Nas décadas posteriores, essas atividades seriam substituídas pelo agronegócio de grãos, mudando a base produtiva e alterando relações de trabalho e formas de produção, bem como a estrutura agrária, e, consequentemente, gerando uma produção espacial diferenciada.

\section{A reestruturação produtiva no setor agrícola e o agronegócio da commodity soja}

A expansão do capital no campo à luz do agronegócio evidencia a conformação de novos territórios no Brasil, com uma tendência à especialização funcional das regiões. Tal conformação espacial deve-se à 
produção de commodities para a exportação, o que demanda do território maiores dinamicidade e fluidez, tomando como base dos meios técnico, científico e informacional, a fim de garantir a compressão espaço-temporal necessária para reduzir os custos da produção e comercialização, ou seja, para garantir a reprodução ampliada do capital. Portanto, estado, multinacionais, corporações do agronegócio e empresas vinculadas à sua cadeia produtiva configuram a dinâmica da reestruturação da base produtiva do setor agrário brasileiro. Para Arruda (2007), esse processo

constitui a manifestação da lógica capitalista na busca pela ordenação espaço-temporal marcada pela modernização do campo via industrialização da agricultura e a posterior consolidação dos Complexos Agroindustriais. Tal processo passa a ocorrer a partir da efetiva reunificação da agricultura em um patamar que supera o simples consumo produtivo pela agricultura, pelo comando da indústria no processo produtivo como fornecedor de bens de capital e insumos para o setor agrícola (capital industrial e financeiro). Em suma, o setor agrícola moderno se converte em um ramo da produção que compra insumos e vende matérias primas para outros ramos industriais, notadamente para as agroindustriais (Graziano da Silva, 1998). Com a intensificação do processo de globalização da economia e o intenso desenvolvimento técnico-científico-informacional, o processo de reestruturação do setor agrário se acentua, no qual a produção agrária e as empresas ligadas ao setor passam a buscar maior modernização e eficiência com o objetivo de diminuir os custos e auferir lucros. (Arruda, 2007, p. 17)

Essa dinâmica da reestruturação produtiva com base no agronegócio das commodities não ocorre de forma homogênea no território brasileiro. Portanto, existem diferenciações socioespaciais que merecem ser trabalhadas de forma atenta.

Cada espaço apresenta suas especificidades, posto que é fruto de ações peculiares e formas diferenciadas, de acordo com os processos que as engendram e particularizam o local. Assim, os agentes utilizam diversas estratégias e realizam estudos e análises para que o capital se materialize em uma determinada localidade, visando a obter desta condições para auferir lucros com menos gastos e maior produtividade em menor tempo.

O agronegócio é uma das atividades que segue essa lógica mediante o uso de análises, estudos e estratégias, ao buscar terras produtivas de preço acessível, infraestrutura e logística para escoar a produção, sistemas de ações incentivadores, como isenções fiscais, e o acesso a créditos. 
Na última década, o agronegócio das commodities no território brasileiro desencadeou as mais diversas transformações socioespaciais, formando novos fronts agrícolas, remodelando espaços, redefinindo formas e funções. Segundo Elias (2008, p.2), com essa difusão formam-se

novas regiões produtivas agrícolas, as quais denominamos de arranjos territoriais produtivos agrícolas. [...] Tal realidade acirra a refuncionalização dos espaços agrícolas e leva à difusão de especializações territoriais produtivas, denotando-se inúmeras seletividades, seja da organização da produção, seja da dinâmica do próprio espaço agrícola. A formação destas regiões produtivas agrícolas obedece aos interesses dos agentes hegemônicos que estão à frente de tais processos, empresas agrícolas nacionais e multinacionais, e isso significa que não seguem necessariamente às divisões políticas administrativas estabelecidas, nem mesmo aos interesses locais, regionais ou mesmo nacionais.

No caso brasileiro, a gestação e efetivação dessas regiões produtivas decorrentes do agronegócio (seja ligado à fruticultura, à soja, ao setor sucroalcooleiro, ou à oferta de carnes, produtos florestais, café e fumo, entre outros) são frutos de um conjunto de forças em articulação. Entre essas forças, devem ser citados o Estado, ao promover políticas públicas, incentivos fiscais e redução de impostos, e as empresa multinacionais e nacionais ligadas à produção, assim como toda a cadeia produtiva, desde a localidade em que os bens são produzidos, até sua chegada ao mercado externo.

Portanto, há uma concentração exacerbada do meio técnico-científico-informacional em algumas regiões do país. Em detrimento de outras, estas regiões beneficiadas servem a um grupo de atividades voltadas para a exportação, demandando recursos públicos para a construção de infraestrutura e redução de impostos, entre outras medidas.

Tais regiões luminosas, bem como as regiões que estão em formação, por concentrarem infraestruturas e condições propícias às atividades do agronegócio, são resultantes da dinâmica do capital de certas empresas e do controle de seus monopólios. Para Arruda (2007, p. 19), a

formação de conglomerados empresariais no setor agrário implicou o aumento da centralização e da concentração do capital dos mesmos, bem como a expansão do seu poder de dominação ao incorporar vastas regiões sob os seus interesses econômicos. Sob essa nova lógica capitalista imperialista as atividades agrárias tornam-se cada vez mais alvo estratégico das corporações agroindustriais em re- 
des que buscam reiteradas vezes aprovisionar os seus recursos, assim como, exercer o controle do processo produtivo até o mercado consumidor. Ou seja, uma subsunção total das atividades agrícolas aos interesses econômicos das grandes corporações agroindustriais nacionais e internacionais que comandam o circuito produtivo do setor agropecuário em escala global.

A produção da commodity soja no Brasil tem se concentrado nas regiões Centro-Oeste do país e vem se expandindo para o Nordeste nos estados do Maranhão, Piauí, Bahia, além da região Norte. Na década de 1990 essa tendência se consolidou nas regiões Nordeste e Norte do Brasil, definindo novas fronteiras.

Os dados da Tabela 1 evidenciam a expansão da produção de soja no país. Nesse recorte temporal de dez anos (1998 a 2008), a produção nacional teve um crescimento de 27.885.156 toneladas em sua produção. No tocante à área ocupada, o acréscimo foi de 7.806.360 hectares, o que torna evidente a expansão do agronegócio da soja no território brasileiro. Os rendimentos também foram satisfatórios, evidenciando avanços nessa atividade produtiva, tais como melhoramento genético, uso de defensivos agrícolas e uso de máquinas sofisticadas que garantem o melhor aproveitamento da colheita. Em 1998, o rendimento foi de 2.366, sendo que no ano de 2008 eleva-se para 2.814 .

A análise da tabela revela a difusão do agronegócio da soja nos estados nordestinos de Bahia, Maranhão e Piauí, considerados em conjunto como a "última fronteira agrícola". No estado do Maranhão, o aumento da produção foi de 971.343 toneladas numa área acrescentada de mais novos 274.084 hectares de terra, tendo no ano de 2008 o rendimento de $2.995 \mathrm{~kg} / \mathrm{ha}$. O estado da Bahia também teve acréscimo na produção e na área de plantio, totalizando, respectivamente, 155.964 toneladas e 351.318 hectares. O estado do Piauí seguiu a mesma tendência da produção da soja verificada nos estados do Maranhão e da Bahia, com o crescimento da área plantada correspondendo a 226.414 hectares em que foram produzidas 769.394 toneladas de soja.

A grande produção de soja no Brasil deve-se a alguns fatores que a lógica vigente trata como potencialidades locais, a saber: as condições favoráveis de solo e clima, a possibilidade de associação com outras culturas, de mecanização da produção, do crescimento da agroindústria, da formação de cooperativas na intermediação e comercialização e a crescente aceitação na dieta alimentar. 
As produções de soja e de outras commodities são colocadas como propostas de crescimento, produtividade e desenvolvimento para suas áreas de produção ou territórios de desenvolvimento, que é outro conceito utilizado nas políticas públicas neste novo contexto.

Tabela 1 - Área plantada e colhida, produção e rendimentos da soja no Brasil (1998-2008)

\begin{tabular}{l|r|r|r|r|r|r}
\hline \multirow{2}{*}{$\begin{array}{l}\text { Unidade da } \\
\text { Federação }\end{array}$} & \multicolumn{2}{c|}{$\begin{array}{c}\text { Área (Plantada e colhida) } \\
\text { (ha) }\end{array}$} & \multicolumn{2}{c|}{$\begin{array}{c}\text { Produção } \\
\text { (t) }\end{array}$} & \multicolumn{2}{c}{$\begin{array}{c}\text { Rendimento } \\
\text { (kg/ha) }\end{array}$} \\
\cline { 2 - 7 } & $\mathbf{1 9 9 8}$ & $\mathbf{2 0 0 8}$ & $\mathbf{1 9 9 8}$ & $\mathbf{2 0 0 8}$ & $\mathbf{1 9 9 8}$ & $\mathbf{2 0 0 8}$ \\
\hline Tocantins & 41.282 & 329.508 & 92.881 & 894.309 & 2.250 & 2.250 \\
\hline Maranhão & 147.436 & 421.520 & 291.322 & 1.262 .665 & 1.977 & 2.995 \\
\hline Piaú & 27.152 & 253.566 & 49.864 & 819.258 & 1.836 & 3.230 \\
\hline Bahia & 553.700 & 905.018 & 1.188 .000 & 2.747 .634 & 2.146 & 3.035 \\
\hline Minas Gerais & 563.987 & 870.602 & 1.281 .695 & 2.566 .350 & 2.273 & 2.962 \\
\hline São Paulo & 525.300 & 525.940 & 1.023 .300 & 1.446 .108 & 1.948 & 2.749 \\
\hline Paraná & 2.848 .000 & 3.969 .113 & 7.286 .000 & 11.800 .466 & 2.558 & 2.973 \\
\hline Santa Catarina & 217.297 & 373.358 & 511.691 & 946.463 & 2.355 & 2.535 \\
\hline Rio de Grande do Sul & 3.163 .429 & 3.804 .425 & 6.605 .743 & 7.679 .939 & 2.088 & 2.019 \\
\hline Mato Grosso do Sul & 1.108 .974 & 1.732 .031 & 2.319 .161 & 4.570 .771 & 2.091 & 2.639 \\
\hline Mato Grosso & 2.643 .389 & 5.470 .149 & 7.228 .052 & 17.212 .351 & 2.734 & 3.146 \\
\hline Goiás & 1.375 .466 & 2.180 .571 & 3.393 .240 & 6.604 .850 & 2.467 & 3.029 \\
\hline Distrito Federal & 35.628 & 48.712 & 86.375 & 153.443 & 2.424 & 3.150 \\
\hline Total & $\mathbf{1 3 . 2 5 0 . 9 9 6}$ & $\mathbf{2 1 . 0 5 7 . 3 0 2}$ & $\mathbf{3 1 . 3 5 7 . 3 2 4}$ & $\mathbf{5 9 . 2 4 2 . 4 8 0}$ & $\mathbf{2 . 3 6 6}$ & $\mathbf{2 . 8 1 4}$ \\
\hline Fonyyyyyyyy
\end{tabular}

Fonte: IBGE-Sindra (2010). Elaborado por Manuela Nunes Leal.

0 agronegócio e a commodity soja no Piauí: novas espacialidades de uma região em conformação

A ocupação dos cerrados piauienses pela atividade do agronegócio iniciou-se nas últimas décadas, mais precisamente a partir da década de 1970. Seu ponto de partida foi a criação de incentivos com base em linhas de crédito do programa Polo Nordeste voltado para médios e grandes proprietários para que estes melhorassem a capacidade produtiva das fazendas, aumentando a produção, viabilizando as exportações e garantindo a demanda nacional por alimentos. 
Posteriormente, várias empresas e produtores buscaram adquirir terras no estado do Piauí, movidos pelo seu baixo preço e pela atratividade dos financiamentos do governo federal com recursos da Superintendência do Desenvolvimento do Nordeste (Sudene), como, por exemplo, o Fundo de Investimentos do Nordeste (Finor), e do Fundo de Investimentos Setoriais (Fiset).

O principal objetivo desses programas e financiamentos que chegaram ao Piauí foi o melhoramento da capacidade produtiva das fazendas tradicionais de gado e a formação de áreas de extrativismo, bem como a realização de projetos de reflorestamento, como, por exemplo, a plantação de mudas de caju.

As pesquisas realizadas revelaram que grande parte desses projetos não se consolidou, o que levou ao aprofundamento da concentração de terras, segundo Monteiro e Aguiar (2006), com base em estudo de caso no município de Uruçuí-PI, que recebeu uma quantidade considerável dos investimentos e de programas citados acima. Houve uma

expressiva quantidade de negócios realizados e o significativo número de transações com grandes propriedades, explicitando que as políticas públicas de fomento à ocupação do cerrado do Piauí incentivam o aprofundamento da concentração da estrutura fundiária no município.

Caráter patrimonialista da ocupação de Uruçuí fica explícito quando se verifica encontrarem-se os projetos instalados, em sua maioria, abandonados e com suas atividades paralisadas, não restando nenhum vestígio da cultura projetada. (Monteiro e Aguiar, 2006, p. 217)

Entretanto, foi somente na década de 1980 e início da década de 1990 que o agronegócio da commodity soja chegou ao sul dos estados do Maranhão e do Piauí, promovendo significativas transformações socioespaciais.

Na década de 1980, o Centro Nacional de Pesquisa de Soja da Embrapa (Embrapa-CNPSO) realizou vários estudos e pesquisas sobre o cultivo da soja no Piauí. Como consequência dessas pesquisas, foi introduzida no Piauí uma linhagem de soja, fruto de uma seleção cultivar, pela Unidade de Execução de Pesquisa Agropecuária Estadual de Teresina (Embrapa-UEPAE Teresina).

Cumpre registrar que desde 1978 já vinham sendo realizadas pesquisas sobre a possibilidade do cultivo de soja no Piauí (Moraes, 2006, p. 189). Quanto à evolução da produção de soja neste estado, pode-se eviden- 
ciar que no ano de 1885 foram produzidas 142 toneladas em 221 hectares. Em dez anos, a produção elevou-se para 20.296 toneladas em 8.635 hectares, e no ano de 2006 a produção chegou a 528.459 toneladas em 216.209 hectares (IBGE-Sindra, 2010).

Conclui-se, dessa feita, que há uma combinação de fatores tecnológicos, econômicos, políticos e sociais imbricados para a conformação da atividade do agronegócio no estado do Piauí. Esse conjunto de ações tinha como propósito a inserção do sudoeste do Piauí na dinâmica em ascensão do agronegócio e sua lógica de reprodução, sendo fundamentais as relações entre os setores público e privado para dinamizar essa atividade. É mister destacar, outrossim, as informações apresentadas por Alves (2004, p. 48) sobre essa questão:

As estratégias de acumulação do capital em terras piauienses são muito semelhantes às adotadas no Oeste da Bahia e Sul do Maranhão, na medida em que se adotam os mesmos mecanismos para a territorialização do capital. Coincidem com a chegada dos primeiros grupos ao Piauí, a implementação de políticas governamentais voltadas para atender a modernização agropecuária naquele Estado, tais como: ampliação das linhas de créditos para a agropecuária e para os reflorestamentos financiados pelo Finor (Fundos de Investimentos do Nordeste), pelo Banco do Nordeste e [Banco] do Brasil; implantação ou melhoramento de infraestrutura viária, de telecomunicações e de energia elétrica; além da grande disponibilidade de terras públicas a preços muito baixos. Tais mecanismos de incentivos econômicos se fortaleceram na década dos $90 \mathrm{com}$ a atuação do Proceder e com as perspectivas previstas para a construção de corredores viários de exportação destinados ao escoamento da produção dessa sub-região aos grandes portos do Nordeste, especialmente ao complexo portuário de Itaqui/Ponta da Madeira, em São Luís (MA). [Grifos da autora]

De região improdutiva para a agricultura de mercado, fundamentada na produção para subsistência, atividade pastoril e extrativista, para uma agricultura moderna do agronegócio, o sudoeste piauiense passou por constantes transformações socioespaciais. Ocorreu uma reestruturação na base produtiva do Piauí em razão de que, no início da década de 1970, a produção agrícola existente nesse território baseava-se na atividade pastoril e agricultura de subsistência nos vales úmidos, bem como no uso dos platôs planos, ou chapadas, para uso de pasto em determinado período do ano, caça de animais para alimentação das famílias, extração de lenha e coleta de frutos (Alves, 2005). 
Na década de 1980 e mais especificamente na década de 1990 essas atividades foram substituídas pelo agronegócio de grãos, principalmente de soja, o que alterou a estrutura produtiva e as formas de produção com a utilização de novas tecnologias como melhoramento genético de grãos, uso de máquinas como tratores e colhedeiras, e defensivos agrícolas, além de produzir mudanças na estrutura agrária nos municípios produtores de soja. Tais mudanças tiveram como consequência uma produção espacial diferenciada, conformando novas espacialidades no espaço rural e urbano. A expansão do agronegócio da soja no Piauí pode ser demonstrada na análise da Tabela 2.

Tabela 2 - Área plantada e colhida, produção e rendimentos da soja no Piauí (1998-2008)

\begin{tabular}{|c|c|c|c|c|c|c|}
\hline \multirow{2}{*}{ Unidade da Federação } & \multicolumn{2}{|c|}{ Área } & \multicolumn{2}{|c|}{ Produção } & \multicolumn{2}{|c|}{ Rendimento } \\
\hline & 1998 & 2008 & 1998 & 2008 & 1998 & 2008 \\
\hline Antônio Almeida & 340 & 3.067 & 198 & 9.937 & 582 & 3.239 \\
\hline Alvorada do Gurgueia & - & 3.800 & - & 12.012 & - & 3.161 \\
\hline Baixa Grande do Ribeiro & 12.307 & 41.408 & 24.840 & 136.646 & 2.018 & 3.299 \\
\hline Bom Jesus & 1.050 & 28.022 & 1.890 & 91.725 & 1.800 & 3.273 \\
\hline Corrente & - & 75 & - & 225 & - & 3000 \\
\hline Cristalândia & - & 80 & - & 240 & - & 3000 \\
\hline Currais & - & 10.776 & - & 34.268 & - & 3.180 \\
\hline Gilbués & 750 & 11.660 & 810 & 37.759 & 1.080 & 3.238 \\
\hline Landri Sales & - & 1.745 & - & 6.073 & - & 3.480 \\
\hline Manoel Emídio & - & 1.375 & - & 4.372 & - & 3.179 \\
\hline Monte Alegre & - & 8.408 & - & 26.694 & - & 3.174 \\
\hline Palmeira do Piauí & 60 & 7.199 & 162 & 22.893 & 2.700 & 3.180 \\
\hline Piracuruca & - & 140 & - & 185 & - & 1.321 \\
\hline Porto Alegre do Piauí & - & 1.000 & - & 2.880 & - & 2.880 \\
\hline Ribeiro Gonçalves & 975 & 40.856 & 1.770 & 129.992 & 1.815 & 3.179 \\
\hline Santa Filomena & 1.870 & 15.915 & 3.764 & 49.250 & 2.012 & 3.094 \\
\hline Sebastião Leal - PI & 280 & 5.240 & 455 & 18.305 & 1.625 & 3.493 \\
\hline Uruçuí - PI & 9.520 & 72.800 & 15.975 & 235.872 & 1.678 & 3.248 \\
\hline Piauí & 27.152 & 253.566 & 49.864 & 819.258 & 1.836 & 3.230 \\
\hline
\end{tabular}

Fonte: IBGE-Sindra (2010). Elaborado por Manuela Nunes Leal.

Segundo dados IBGE-Sindra (2010), o agronegócio da soja no Piauí apresentou crescimento da área plantada. Em um período de dez anos, 
o acréscimo teve variação absoluta de 226.414 h e variação relativa de 833,87\%. Quanto à produção de soja neste mesmo recorte temporal, o crescimento foi de 769.394 toneladas, o que representou uma variação absoluta de 769.394 toneladas e variação relativa de 1.542,98\%. Este período de expansão da atividade do agronegócio da soja no território do Piaú, bem como de incremento da produção, foi acompanhado por um rendimento satisfatório de $3.230 \mathrm{~kg} / \mathrm{h}$ evidenciando uma maior produtividade desta commodity.

Tal incremento da produção e área plantada deve-se à maior produtividade dos municípios que já produziam a commodity bem como à expansão deste cultivo em outros municípios que ainda não eram produtores no ano de 1998, já que esta produção é bem recente. A partir do ano de 2007, podem ser citados os seguintes municípios produtores de soja: Antônio Almeida, Alvorada do Gurgueia, Currais, Landri Sales, Manoel Emídio, Monte Alegre do Piauí, Piracuruca, Porto Alegre do Piauí (IBGE-Sindra, 2010). Os maiores produtores de soja no Piauí são os municípios de Baixa Grande do Ribeiro, Bom Jesus, Ribeiro Gonçalves e Uruçuí, acompanhando-se o recorte temporal de 1998 a 2008.

A expansão da soja no território do Piauí é resultado de várias ações em prol da consolidação do agronegócio desse produto no sudoeste do estado. O governo do estado, a iniciativa privada e a sociedade civil organizada implementaram ações em defesa do agronegócio de mercado, como infraestrutura necessária e créditos para base produtiva local e regional.

Para tais fins, foi criado o Polo Uruçuí/Gurgueia, estratégico para o desenvolvimento desse agronegócio, que foi assim caracterizado:

Localizado no sul do Piauí, afigura-se como uma das áreas de maior potencial de desenvolvimento do complexo agroindustrial nas áreas dos cerrados nordestinos, estando hoje integrado ao processo de expansão da sojicultura para as fronteiras agrícolas do Nordeste e do Centro-Oeste. O Polo detém recursos naturais e vantagens comparativas significativas para seu crescimento e dinamização de toda a área sob sua influência, pelo que tem atraído o interesse crescente de governos e de investidores privados, internos e externos, dos vários elos da cadeia produtiva. (Piauí, p. 11)

Os documentos elaborados pelo estado e os discursos de políticos locais evidenciaram a necessidade da superação da região improdutiva, do vazio populacional e de baixos indicadores sociais, posto que o sudoeste do estado demandava uma saída para o seu desenvolvimento. 
É pertinente ressaltar os reais objetivos disso: a necessidade de enaltecer e consolidar esse espaço como última fronteira agrícola, buscando atrair investidores e empresas que se insiram na lógica do capital tomando como base a reestruturação produtiva via agronegócio de grãos. É mister ressaltar as afirmações de Moraes (2006) quanto à necessidade de uma

visibilidade nova para o Piauí [que], ao incorporar a região sudoeste do estado como produtora de riquezas oriundas da agricultura, requeria estudos e levantamentos promotores da visibilidade daquela parte do espaço considerada, ate então, um vazio e cuja contraface passava a ser, agora, a frente de expansão para o agronegócio do complexo carnes/grãos e, até, um "celeiro de alimentos básicos"! Nesse sentido, era preciso reiventar o Piauí e ressemantizar uma região.

[...] Na metamorfose do vazio em potencialidade e na negação do destino pecuarista, torna-se mister dar publicidade não só ao esforço do governo, mas também ao interesse que a região dos cerrados e a recém-descoberta vocação agrícola despertavam nos novos investidores. (Moraes, 2006, p. 188-189)

Assim, essa conformação de ideias e ações é responsável pela inserção do Piauí no mercado da commodity soja e a materialização de todo seu arranjo territorial necessário à produção, comercialização e distribuição para as agroindústrias ou para o mercado externo.

O agronegócio tem estabelecido suas bases no território dos cerrados piauienses valendo-se da conformação de arranjos produtivos, ou seja, fazendas com produção de grãos, indústria processadora, como a Bunge Alimentos no município de Uruçuí, e todo um circuito produtivo.

Além disso, vários serviços vêm-se materializando nos núcleos urbanos para dar suporte à atividade do agronegócio, tais como: rede bancária, prestadores de serviços, consultoria, comercialização de insumos e maquinários para as fazendas, entre outros.

Tais atividades compõem a cadeia produtiva do agronegócio neste novo cenário da economia flexível e de reestruturação produtiva. Sobre essa realidade no cerrado nordestino, Elias (2006, p. 37) ressalta que a formação de um

arranjo territorial produtivo compõe uma nova região de produção agrícola globalizada, cujos nexos organizacionais são comandados de forma oligopsônica pelas multinacionais Cargill e Bunge. Neste arranjo produtivo, estas duas multinacionais comandam a produ- 
ção de soja por parte de centenas de médios e grandes empresários agrícolas. Apesar de não atuarem na produção agrícola diretamente, dominam a produção por meio da compra e da moagem do grão, compondo um tipo específico de parceria no qual o principal elo de dependência entre os empresários agrícolas e as agroindústrias se dá pelo empréstimo de capital que estas fazem aos primeiros.

Estado, empresas, agroindústrias, produtores e prestadoras de serviços, como o serviço de logística, compõem os agentes que organizam o rural e o urbano no sudoeste piauiense, conformando uma região produtora da commotidy soja. A ação de cada um desses agentes resulta na criação de formas espaciais de funções novas ou na alteração de significados das já existentes, (re)ordenando o espaço piauiense em obediência à lógica do capital transformador. Sobre tais dinâmicas, Moyses e Silva (2007, p. 6) ressaltam:

Não resta dúvida de que os investimentos públicos e privados alocados por conta dos incentivos e programas governamentais foram de extrema importância para o crescimento da região, na medida em que proporcionaram um grande dinamismo econômico local, ao mesmo tempo em que asseguraram a sua integração à economia nacional. No entanto, cabem algumas ponderações quanto aos efeitos decorrentes desse aporte maciço de investimento, pois, se de um lado eles lhe deram um novo perfil econômico, de outro, deram também uma nova feição social às suas cidades, sobretudo àquelas que mais se desenvolveram.

Tais estratégias para viabilizar a reestruturação produtiva via agronegócio no Piauí desencadeiam uma dinâmica socioespacial que traz consigo algumas consequências para o espaço agrário e urbano no que diz respeito à mobilidade do capital. As mudanças mais comuns ocorrem nas relações de trabalho, no incremento populacional nos núcleos urbanos que causam a periferização, na subordinação ou dependência dos produtores à agroindústria, e na especulação imobiliária e fundiária.

Algumas dessas consequências da reestruturação produtiva são o redirecionamento dos fluxos de pessoas, ou seja, o êxodo rural das famílias para as cidades mais próximas, a busca por moradias no núcleo urbano por parte dos produtores de soja, os fluxos de estudantes para as novas universidades que se direcionam para os municípios produtores de commodity e pela busca por emprego nos serviços atrelados à cadeia produtiva. Esse redirecionamento dos fluxos de pessoas, seja para trabalho, estudo ou moradia, é responsável por modificações na produção espacial, 
mediante a criação de novas espacialidades no espaço urbano destes municípios, como é o caso do município de Bom Jesus-PI, onde,

em razão do aumento da população urbana ocorrida pelos constantes movimentos migratórios, pela atração de estudantes pelos ensinos médios e superiores, pela chegada de novos trabalhadores para as novas oportunidades de serviços, observou-se que existe uma preocupação por parte da população para que sejam construídas novas unidades habitacionais, pois nos últimos anos houve um aumento do preço dos alugueis na cidade. O crescimento de moradias de baixa renda na periferia, próximas ao cemitério e ao aterro sanitário, sem sistema de esgoto e com ruas sem pavimentação, situadas em relevo extremamente acidentado, ocorre em função das condições criadas. (Façanha e Leal, 2009, p. 145)

Esta é uma realidade em Bom Jesus, bem como em municípios em que a reestruturação produtiva via agronegócio tem se materializado no Piauí.

A estrutura fundiária atual dos municípios produtores de soja do Piauí é um indicador dessas mudanças necessárias à reestruturação produtiva, posto que evidencia a concentração das terras em grandes propriedades necessárias à produção de grão, bem como a especulação existente, que exclui o pequeno produtor do acesso à terra, ocasionando em parte o êxodo rural. Segundo Brandão (2009), utilizando dados de 2005,

nos municípios do arranjo produtivo da soja piauiense há visível concentração fundiária nas grandes propriedades. Observa-se que a maioria dos municípios concentra mais de $70 \%$ de suas áreas no segmento grande propriedade, destacando Baixa Grande do Ribeiro com $79,37 \%$ da área total. A média propriedade concentra 17,48\%, as pequenas ocupam $6,21 \%$ e os minifúndio apenas 1,29\%. (Brandão Filho, 2009, p. 124)

Como já foi evidenciado, antes da atividade do agronegócio existia a agricultura de subsistência, a pequena produção e a pecuária, ou seja, predominavam os minifúndios e a média propriedade com os projetos financiados no final da década de 1970. O agronegócio da soja teve o poder de mudar a estrutura fundiária, posto que o número de pequenas propriedades nesses municípios produtores de soja se restringe a 1, 29\%.

A difusão da soja no cerrado piauiense redirecionou investimentos e infraestrutura para esse espaço do estado piauiense, atraindo fluxos de migrantes e empresas relacionadas a essa atividade, desterritorializando 
parte da atividade pastoril e de subsistência e territorializando a agricultura científica para o mercado externo.

Novos estudos devem ser realizados para melhor compreender a produção de novas espacialidades no rural e no urbano no Piauí em razão da reestruturação produtiva via agronegócio da commodity soja, dando especial destaque a seu papel na conformação de uma região produtora de soja. O desafio dessa análise será focalizado na tese em construção atualmente pela autora Manuela Nunes Leal, com a orientação de Vera Lucia Alves França.

\section{Considerações finais}

A reorganização espacial da produção da soja no estado do Piauí, mais especificamente no sudoeste desse estado, em novas áreas de expansão, é resultante de uma nova fase do capitalismo, no caso do capitalismo flexível, caracterizado pela reestruturação produtiva.

Em sua lógica, o capital busca os espaços atrativos com disponibilidade de terras, incentivos fiscais, mão-de-obra barata e fraca organização sindical, condições de fluidez de informações, capital e pessoas para garantir sua reprodução de forma rentável. Para atingir seus objetivos lucrativos, o capital necessita, pois, de uma mobilidade de capitais, mão-de-obra e ações para regionalizar a atividade econômica do agronegócio, uma cadeia de commodities fundamentada em alocações que lhe são convenientes, nem que para tanto seja necessário desterritorializar o pequeno produtor para ceder espaço à agricultura voltada para o mercado externo. Cria-se, pois, espaços diferenciados pela técnica, onde ocorrerá a concentração de infraestrutura e serviços em detrimento de outros espaços, na lógica do capital transformado que é desigual e combinado.

Seria sinônimo de desenvolvimento e prosperidade essa nova dinâmica no território piauiense, tendo em vista que esse espaço apresenta situação social desigual, caracterizada por baixos indicadores sociais, como assinala documento do Ministério da Integração Nacional na Cartilha do Programa de Promoção da Sustentabilidade de Espaços Sub-Regionais (Brasil, [s.d.]), referente à Mesorregião da Chapada das Mangabeiras.

Ponderações a ser feitas a esse respeito, demandam novos estudos sobre a reestruturação produtiva levando em consideração o agronegócio e o seu papel na organização do espaço agrário e nas regiões produtivas 
da soja, discutindo a relação campo-cidade, de forma a buscar compreender as tendências em gestação de regiões da commodity soja no estado do Piauí.

\section{Referências}

ALVES, Vicente. Os cerrados piauienses e sua nova lógica de reprodução capitalista. In: ELIAS, Denise; PEQUENO, Renato (Org.). Difusão do agronegócio e novas dinâmicas socioespaciais. Fortaleza: Banco do Nordeste do Brasil, 2006. p. 235-258.

ALVES, Vicente. A expansão da soja e o processo de urbanização nos cerrados piauienses. In: ENCONTRO DE GEÓGRAFOS DA AMÉRICA LATTINA: DO LABIRINTO DA SOLIDÃO AO ESPAÇO DA SOLIDARIEDADE, 10, 2005, São Paulo. Anais... São Paulo: Departamento de Geografia/FFLCH/USP, 2005.

ARRUDA, Zuleika Alves de. Onde está o agro desse negócio? transformações socioespaciais em Mato Grosso decorrentes do agronegócio. Campinas, 2007. 253p. Tese (Doutorado em Geografia) - Instituto de Geociências, Universidade Estadual de Campinas, Campinas, 2007.

BRANDÃO FILHO, José. Dilemas e desafios da pequena produção agrícola frente à expansão do agronegócio. In: BERNARDES, Júlia (Org.). A territorialidade do capital. Rio de Janeiro: Arquimedes, 2009. 115 p.

BRASIL, Ministério da Integração Nacional. Cartilha do Programa de Promoção da Sustentabilidade de Espaços Sub-Regionais. Disponível em: <http://www. integracao.gov.br/programasregionais/publicacoes/promeso.asp $>$. Acesso em: 10/1/2010.

ELIAS, Denise. Ensaios sobre os espaços agrícolas de exclusão. Revista Nera (Presidente Prudente-SP), n. 8, jan./jun. p. 29-51, 2006.

ELIAS, Denise. Redes agroindustriais e urbanização dispersa no Brasil. In: COLOQUIO INTERNACIONAL DE GEOGRÍTICA: DIEZ AÑOS DE CAMBIOS EN EL MUNDO, EN LA GEOGRAFÍA Y EN LAS CIENCIAS SOCIALES - 1999-2008, 10, 2008, Barcelona. Disponível em: <http://www.ub.es/geocrit/-xcol/270.htm>. Acesso em: 18/6/2009.

FAÇANHA, Antonio; LEAL, Manuela. Transformações no urbano do Piauí: o caso de Bom Jesus. In: BERNARDES, Júlia (Org.). Geografia da soja II: a territorialidade do capital. Rio de Janeiro: Arquimedes, 2009. 137 p.

MONTEIRO, Maria do Socorro; AGUIAR, Teresinha de Jesus. Ocupação do cerrado piauiense: valorização fundiária e consequências ambientais. In: ELIAS, Denise; PEQUENO, Renato. Difusão do agronegócio e novas dinâmicas socioespaciais. Fortaleza: Banco do Nordeste do Brasil, 2006. p. 211-233.

MOYSÉS, Aristides. SILVA, Eduardo. Ocupação e urbanização dos cerrados do centro-oeste e a formação de uma rede urbana concentrada e desigual. In: XII ENCONTRO DA ASSOCIAÇÃO NACIONAL DE PÓS-GRADUAÇÃO E PESQUISA 
EM PLANEJAMENTO URBANO E REGIONAL 21 a 25 de maio de 2007 Belém-Pará - Brasil.

MORAES, Maria Dione. Do pastoril à vocação agrícola: modernização agrícola dos cerrados e inflexões discursivas nas narrativas mestras do Piauí. In: ELIAS, Denise; PEQUENO, Renato. Difusão do agronegócio e novas dinâmicas socioespaciais. Fortaleza: Banco do Nordeste do Brasil, 2006. p. 173-209.

PIAUÍ. Documento Referencial do Pólo de Desenvolvimento Integrado Uruçuí/Gurgueia do Estado do Piauí. Disponível em: http://www.bnb.gov.br/content/Aplicacao/ETENE/Rede_Irrigacao/Docs/Documento. Urucui-Gurgueia.PDF. Acesso em 10/1/2010.

IBGE - Instituto Brasileiro de Geografia e Estatística. Sistema IBGE de Recuperação Automática-Sindra. Disponível em http://www.sidra.ibge.gov.br/. Acesso em: 10/1/2010.

Manuela Nunes Leal - Doutoranda do Programa de Pós-Graduação em Geografia pela Universidade Federal de Sergipe e professora da Universidade Estadual de Feira de Santana-UEFS.

Vera Lucia Alves França - Doutora em geografia pela Universidade Estadual Paulista Júlio de Mesquita Filho e professora aposentada da Universidade Federal de Sergipe. 